\title{
Retrocessos na política nacional de saúde mental: consequências para o paradigma psicossocial
}

\author{
Regressions in the national mental health policy: \\ consequences for the psychosocial paradigm
}

José Guilherme Nogueira Passarinho*

\begin{abstract}
Resumo - Trata-se de um ensaio teórico acerca das principais alterações feitas na política nacional de saúde mental no período de 2016 a 2020, período em que se institui a chamada "nova política nacional de saúde mental". Nesse sentido, endossa-se o argumento de diversos autores que qualificaram as novas orientações como retrocessos com relação às conquistas da reforma psiquiátrica brasileira. Pretende-se fundamentar nesse contexto a pertinência do emprego de termos como "retrocesso" e "contrarreforma", destacando sobretudo os aspectos éticos e políticos implicados nessas caracterizações. Para tanto, foi utilizada a análise paradigmática dos modos antagônicos de produzir atenção em saúde mental, que possibilitou demonstrar o tensionamento estabelecido pelas novas legislações com os postulados da reforma psiquiátrica e da atenção psicossocial.

Palavras-Chave: atenção psicossocial; reforma psiquiátrica; política nacional de saúde mental.
\end{abstract}

\begin{abstract}
This theoretical essay discuss the main changes in the Brazilian National Mental Health Policy in the period from 2016 to 2020, when the so-called 'New National Mental Health Policy' is instituted. In this sense, we endorse the argument of several authors who qualified the new guidelines as regressions in face of the achievements of the Brazilian Psychiatric Reform. In this context, this essay is intended as a justification for the pertinence of terms such as 'regression' and 'counter-reformation', highlighting above all the ethical and political aspects involved in these characterizations. For that, we did a paradigmatic analysis of the antagonistic ways of producing mental health care, which allowed to demonstrate the tension established by new legislation with the postulates of the Psychiatric Reform and Psychosocial Care.

Keywords: psychosocial care; psychiatric reform; National Mental Health Policy.
\end{abstract}

\footnotetext{
* Graduado e Mestre em Psicologia na Universidade Estadual Paulista "Júlio de Mesquita Filho" - Faculdade de Ciências e Letras de Assis. E-mail: guilherme.nogueira.passarinho@gmail.com. ORCID: https://orcid.org/0000-00015076-412X.
} 


\section{Introdução}

Ao menos nos últimos quatro anos, diversos artigos têm enfatizado o caráter de descontinuidade da política de Estado para o campo da saúde mental (PASSOS, 2017; ONOCKO-CAMPOS, 2019; NUNES et al., 2019; MORAES FILHO et al., 2019; CRUZ et al., 2020; SILVA et al., 2021). Isso se deve à publicação de uma série de documentos normativos que indicam de modo inequívoco uma alteração no rumo que vinha sendo tomado pelo Ministério da Saúde (MS) nas últimas décadas, até então orientado pelos princípios da reforma psiquiátrica brasileira ( $\mathrm{RPb})$. Por conta disso, tais autores não têm hesitado em qualificar essas alterações como "retrocessos", em descrevê-las como "retorno ao modelo manicomial", ou em nomeá-las como uma "contrarreforma psiquiátrica". Ainda que os métodos, conceitos e argumentos empregados sejam os mais diversos, todos convergem ao afirmar um aspecto de retorno ao modelo anterior à reforma.

O MS tem nomeado esse conjunto de documentos como "nova política nacional de saúde mental", designação empregada em nota oficial do ministério (MINISTÉRIO DA SAÚDE, 2020). Destacamos o sentido de ruptura que essa expressão veicula, bem como sua conotação positiva. São os documentos reunidos sob tal designação ${ }^{1}$ que compõem o recorte deste trabalho, uma vez que é a partir deles que podemos delinear as questões que pretendemos discutir. Certamente existe uma convergência entre o ministério e os autores que comentamos acima, ao menos em relação ao caráter de descontinuidade representado por tais normativas. Mas a discordância se inicia ao se discutir o significado dessas mudanças. Afinal, elas seriam simples atualizações de acordo com novas descobertas científicas, correções de rota sem quaisquer relações para além do debate teóricotécnico; ou devemos compreendê-las como a reação política de um modelo já bastante conhecido, ainda que munido com novos argumentos?

No presente trabalho pretendemos endossar os argumentos que buscam qualificar essas normativas como marcos de um movimento histórico de inflexão da $\mathrm{RPb}$, sendo esta última entendida como um processo social complexo de mudanças nas formas de conceber o sofrimento psíquico e de produzir atenção em saúde mental, cujos princípios teóricos, éticos e políticos apontam para a necessidade da superação do modelo manicomial (YASUI, 2010). Consideramos que essa superação começou a se desenhar no interior do processo da reforma a partir de seus desdobramentos criativos em novas práxis em saúde mental, em um conjunto de inovações técnicoassistenciais que podem ser reunidas sob o nome de estratégias da atenção psicossocial (Eaps) (YASUI; COSTA-ROSA, 2008). Essas estratégias, por sua vez, devem ser balizadas por uma nova forma de produzir atenção ao

\footnotetext{
1 Os documentos reunidos sob essa designação podem ser visualizados nesta página do Ministério do Desenvolvimento Social: http://mds.gov.br/obid/nova-politica-nacional-de-saude-mental.
} 


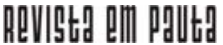

\} RETROCESSOS NA POLITICA NACIONAL - PASSARINHO, J. G. N. \}

DOI: $10.12957 /$ REP.2022.63451

sofrimento psíquico, que chamaremos de modo ou paradigma psicossocial (PPS) (COSTA-ROSA, 2000; 2013), deduzível tanto da negação lógica das estruturas do modelo manicomial, quanto das experiências inovadoras da reforma.

É com base nesses conceitos, Eaps e PPS, que pretendemos contribuir com o debate no sentido de fundamentar o caráter de contrarreforma em curso na política nacional de saúde mental (PNSM). Em outras palavras, ao nos orientarmos pelos parâmetros identificados como paradigmáticos na produção de atenção em saúde mental, buscamos confrontar o conteúdo da "nova" política com os postulados da RPb e da atenção psicossocial. Essa abordagem é importante não apenas por conferir certo rigor ao emprego de termos como "retrocesso" e "contrarreforma", mas também devido à estratégia discursiva empregada nos documentos analisados que, mesmo alterando substancialmente o conteúdo da PNSM, continuam a utilizar em seus enunciados a terminologia típica da atenção psicossocial, numa tentativa ideológica de escamotear seus pressupostos teóricos, seu posicionamento ético e sua intencionalidade política (NUNES et al., 2019; PASSARINHO, 2020). São exatamente esses aspectos, dissimulados no discurso manifesto da "nova" política, que se pretende evidenciar neste trabalho.

Para tanto, foi realizada uma breve exposição das principais portarias, resoluções, notas técnicas e leis publicadas entre 2016 e 2020, período em que foram publicados os documentos que compõem a chamada "nova política nacional de saúde mental". Em seguida, apresentamos o referencial teórico-conceitual empregado em nossa leitura, para então fundamentar o caráter de retrocesso implicado nesses documentos, delineado a partir dos tensionamentos que estabelecem com a RPb e a atenção psicossocial. Dessa forma, pretendemos fazer emergir não apenas os aspectos técnicos envolvidos na questão, mas também os teóricos, éticos e políticos.

\section{Um panorama das alterações na política nacional de saúde mental (2016-2020)}

É certo que algumas das principais vitórias da reforma psiquiátrica brasileira se deram no âmbito jurídico-político, a exemplo da aprovação de uma série de legislações, a maioria delas nas décadas de 1990 e 2000, que versam sobre o cuidado em saúde mental na perspectiva psicossocial e visam à garantia de direitos básicos (AMARANTE, 2000; YASUI, 2010; VASCONCELOS, 2016). Ainda que com consideráveis limitações, esses documentos estão em consonância com os princípios da atenção psicossocial e contribuem para a sua efetivação. A tendência pró-reforma deu o tom da política de Estado, com certa constância, até o início da década de 2010, momento em que é possível identificar o início de uma inflexão. Sobre isso, enquanto alguns pesquisadores destacam a diminuição no ritmo 


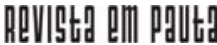

\} RETROCESSOS NA POLÍTICA NACIONAL - PASSARINHO, J. G. N. \}

DOI: $10.12957 /$ REP.2022.63451

de implantação e implementação dos serviços substitutivos e a insuficiência de seu financiamento (ONOCKO-CAMPOS, 2019; CRUZ et al., 2020), outros chamam a atenção para o enfraquecimento da mobilização pela $\mathrm{RPb}$ e para os desafios postos pelo cenário político-econômico mais amplo (VASCONCELOS, 2016).

Com efeito, os retrocessos na $\mathrm{RPb}$ e as lutas contra isso já se marcam no início da segunda década do século XXI, sobretudo com a introdução das comunidades terapêuticas na Rede de Atenção Psicossocial (Raps) em 2011 (VASCONCELOS, 2016; PASSOS, 2017; RAMÔA; TEIXEIRA; BELMONTE, 2019). Contudo, esse processo encontrou condições favoráveis com o cenário político posto a partir de 2015, quando observamos o avanço de forças que se situam no espectro do conservadorismo político, aproveitando-se de uma conjuntura político-econômica que combinou "forte recessão, alto desemprego, crise fiscal dos governos federal, estaduais e municipais [...], e uma gestão conservadora e de baixa competência para o setor" (VASCONCELOS, 2016, p. 68). O projeto explícito desses atores é o de romper de forma radical com a herança deixada pelos governos de centro-esquerda, o que inclui as orientações até então vigentes para a política de saúde mental. Assim, a partir de 2016, tem início a publicação das normativas que compõe o recorte deste trabalho.

Por seu conteúdo, a Portaria no 1.482 do MS (BRASIL, 2016), ainda que não tenha sido incluída oficialmente na chamada "nova política nacional de saúde mental", iniciou de fato a sucessão de documentos que representam o aprofundamento de uma ruptura da política oficial do ministério com os princípios da RPb. Nela temos a inédita admissão das comunidades terapêuticas (CTs) no Cadastro Nacional de Estabelecimentos de Saúde (CNES), facilitando o seu financiamento com recursos públicos. Em 2017, a Resolução no 32 da Comissão Intergestores Tripartite (CIT) elaborou, em termos bastante vagos, novos critérios de monitoramento, avaliação e regulação para a Raps (BRASIL, 2017a). Os hospitais psiquiátricos foram incluídos pela primeira vez na Raps, e a eles foi garantido um reajuste escalonado do valor das diárias de internações. O mesmo documento versa sobre o compromisso de "fortalecer a parceria e o apoio [...] em relação as Comunidades Terapêuticas" (BRASIL, 2017a, p. 239).

Essa resolução apresentou ainda um novo serviço chamado CapsAD IV, que também passou a integrar a Raps e que foi descrito de forma mais detalhada na Portaria no 3.588 do MS (BRASIL, 2017b). À primeira vista, ele é apresentado com terminologias típicas da atenção psicossocial, como um estabelecimento que deverá funcionar como um serviço aberto, com base na territorialidade, no vínculo terapêutico com um profissional de referência, na interdisciplinaridade, entre outros predicados que sempre foram considerados característicos da atenção psicossocial. Em contrapartida, alguns de seus contornos diferem flagrantemente dos traços típicos das outras modalidades desse dispositivo, a exemplo do enfoque na urgência 


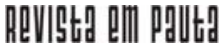

\} RETROCESSOS NA POLITICA NACIONAL - PASSARINHO, J. G. N. \}

DOI: $10.12957 /$ REP.2022.63451

e emergência, de sua localização em cenas abertas de uso e do fato de que poderá contar com até 30 leitos de enfermaria. No ano seguinte, o MS incluiu o Caps-AD IV no CNES com a publicação da Portaria no 544 (BRASIL, 2018).

Em fevereiro de 2019 é publicada a Nota Técnica $n^{\circ}$ 11/2019 (BRASIL, 2019), documento que reúne uma série de portarias e resoluções anteriores, publicadas entre dezembro de 2017 e janeiro de 2018. Salvo a Portaria $n^{\circ} 1.482 / 2016$, todos os outros documentos que abordamos até agora foram incluídos nessa nota, além de quase todos os outros documentos que compõem a "nova política nacional de saúde mental". É nela que aparece enunciado pela primeira vez que esse conjunto de documentos compõe uma "nova" política, em nítido contraste com o discurso adotado até então, em que se afirmava a todo o momento que as mudanças se tratavam apenas de tentativas de fortalecimento da Raps, negando qualquer aspecto de descontinuidade com as orientações anteriores.

Ainda assim, as referências e categorias da atenção psicossocial continuaram aparecendo. Logo em suas primeiras páginas, lemos sobre a necessidade de se expandir os serviços de residências terapêuticas (RTs) e de sua importância para a "desinstitucionalização dos que moram em Hospitais Psiquiátricos" (BRASIL, 2019, p. 4). O documento versa ainda sobre a importância de uma rede assistencial plural, que produza uma atenção integral e que respeite a especificidade de cada demanda, buscando promover maior participação dos usuários. Curiosamente, é dito logo em seguida que não se considera mais nenhum serviço como substitutivo a outro, colocando estabelecimentos asilares e Caps no mesmo patamar dentro da Raps, insinuando que todos devem coexistir harmonicamente na perspectiva da complementariedade. Outro ponto polêmico é o incentivo à oferta da eletroconvulsoterapia (ECT), também chamado de eletrochoque, tratamento historicamente usado pelo modelo manicomial.

Alguns desses documentos, como a Nota Técnica no 11/2019, chegaram a ser retiradas da página oficial do MS após repercussões negativas, e a maioria das mudanças propostas ainda não foram implementadas em âmbito nacional. Não obstante, eles certamente indicam os caminhos que a chamada "nova" política pretende trilhar e em que pontos ela diverge dos princípios da atenção psicossocial e dos objetivos históricos da RPb. Para fundamentarmos um pouco melhor no que consiste esses tensionamentos e como eles se estabelecem, buscaremos conceituar os dois modos fundamentais de produção de atenção e cuidado em saúde mental em disputa por hegemonia em nosso momento histórico.

\section{Dois modos de produção de atenção em saúde mental}

Do ponto de vista histórico, podemos dizer que a atenção psicossocial se constituiu como um desdobramento do processo social de 
contestação da forma como a sociedade brasileira lidava com o fenômeno denominado "loucura", baseada na objetificação do sujeito e em sua reclusão em instituições disciplinares. Esse processo ficou conhecido pelo nome de reforma psiquiátrica brasileira (RPb) (AMARANTE, 2000; COSTAROSA, 2013). A RPb, portanto, se caracteriza por um conjunto de eventos, conflitos e acontecimentos que questionaram o modelo manicomial, protagonizados por atores sociais específicos, os movimentos de trabaIhadores, usuários e familiares das instituições de saúde mental (AMARANTE, 2000). Seu início se localiza no tempo - a partir do final da década de 1960 - e no espaço - inicialmente na Região Sudeste, para depois se generalizar por todo o país (DEVERA; COSTA-ROSA, 2007).

Uma vez que o modelo manicomial produziu episódios flagrantes de violação de direitos elementares, é natural que a RPb tenha se focado, em um primeiro momento, na crítica e denúncia dos efeitos mais nocivos desse modelo. Contanto, seu período inicial foi marcado pela constituição de um discurso contrário aos manicômios e suas práticas. Apenas em um período posterior a $\mathrm{RPb}$ começou a se traduzir em novas práticas, saberes e até mesmo em novos dispositivos institucionais, que buscaram operar em uma lógica que visava à superação do modelo manicomial (COSTA-ROSA; 2000; 2013). Com a criação desses novos dispositivos, em especial os Centros de Atenção Psicossocial (Caps) e os Núcleos de Atenção Psicossocial (Naps), tornou-se possível pensar em tal superação não apenas a partir de um discurso que postula uma crítica com base em determinado ideário éticopolítico, mas também de práticas que buscam positivar esse discurso em termos de táticas e estratégias que produzam uma ampla e profunda transformação no modo como a sociedade se relaciona com as diferentes formas de sofrimento psíquico.

Essa transformação pode ser conceituada como desinstitucionalização da loucura (AMARANTE, 1996; BASAGLIA, 2001) e constitui um dos objetivos que deve ser deduzido de uma ética que não toma os sujeitos em sofrimento como objetos a serem conhecidos e controlados, isto é, como uma doença a ser suprimida (COSTA-ROSA, 2013). Evidentemente, as práticas alinhadas à ética da atenção psicossocial não podem se amparar nos saberes tradicionais e hegemônicos da psiquiatria, próprios do modelo manicomial que se pretende superar, mas em elaborações teóricas críticas e em novos saberes e fazeres, convergentes ao horizonte de transformações para o qual aponta a experiência da reforma e de seus desdobramentos mais radicais, como a atenção psicossocial e a luta antimanicomial.

É a partir do momento em que surgem os novos dispositivos institucionais que se justifica falar em uma estratégia da atenção psicossocial (Eaps), como um "conjunto amplo de transformações práticas e de proposições teóricas, éticas e políticas incorporado e vivenciado na atual Política de Saúde Mental" (COSTA-ROSA; YASUI, 2008, p. 28) e que visa a uma 


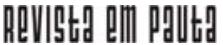

\} RETROCESSOS NA POLÍTICA NACIONAL - PASSARINHO, J. G. N. \}

DOI: $10.12957 /$ REP.2022.6345

"transformação da assistência [...] que não se limita ou se esgota em sua implantação como um serviço de saúde" (COSTA-ROSA; YASUI, 2008, p. 36 - grifos nossos). Ou seja, não houve apenas uma profusão de novos saberes e práticas que formaram uma estratégia orientada para o horizonte ético-político da desinstitucionalização, mas também um reconhecimento e incentivo dado a elas pela política oficial do MS. O objetivo maior dessa estratégia é a transformação das modalidades de relacionamento da sociedade com os sujeitos que sofrem tais crises e impasses. Assim, podemos afirmar que a atenção psicossocial, enquanto estratégia, aponta para a superação radical das instituições do modelo manicomial e sua substituição por novos dispositivos institucionais e novas formas de relação com os sujeitos e seu sofrimento. Daí a importância do conceito de "serviços substitutivos", incluído na legislação da PNSM.

É possível afirmar que instituir novas formas de produzir cuidado ao sofrimento psíquico significa, ao mesmo tempo, produzir outros modos de sociabilidade para os sujeitos que experimentam esse sofrimento. São novas formas de relação social concernentes ao processo de produção de saúde-adoecimento-atenção ao sofrimento psíquico, que exigem a elaboração de respostas organizadas por meio de diferentes dispositivos institucionais. Temos então que o eixo da atenção nesse processo de saúdeadoecimento coincide com a mediação necessária das instituições na produção de respostas a esse sofrimento (COSTA-ROSA, 2013). Mas, se em nosso momento histórico a mediação institucional é uma constante na produção de atenção aos diferentes impasses psíquicos, o modo como essa produção se organiza apresenta importantes variações.

Podemos evidenciar, inicialmente, o modelo que chamamos de modo asilar ou manicomial, cujas características mais evidentes são a utilização de estabelecimentos asilares, a centralidade do saber psiquiátrico e a objetificação dos sujeitos, que são colocados em parênteses para que se dê destaque à doença ou transtorno que o acompanha (BASAGLIA, 2001). Em contrapartida, existe o modo psicossocial, que postula uma forma radicalmente diversa de organizar o eixo da atenção nos processos de saúdeadoecimento psíquico, criando novos dispositivos institucionais que apostam na multiplicidade e transversalidade dos saberes envolvidos na prática do cuidado e colocam em primeiro plano o próprio sujeito (COSTA-ROSA, 2000).

É certo que a experiência cotidiana nos estabelecimentos institucionais nos confrontam com formas muitas vezes heterogêneas, que mesclam diferentes características desses dois modos de produzir atenção (MONDONI; COSTA-ROSA, 2010). As fronteiras entre eles, portanto, podem se tornar opacas, exigindo da teoria uma análise capaz de distinguir os elementos fundamentais desses modos antagônicos, que acima descrevemos apenas em suas características mais imediatas. Ou seja, exige-se uma análise que resulte em uma elaboração conceitual que possa evidenciar os traços 


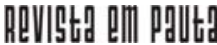

\} RETROCESSOS NA POLÍTICA NACIONAL - PASSARINHO, J. G. N. \}

DOI: $10.12957 /$ REP.2022.63451

fundamentais desses modos antagônicos, que ainda hoje lutam pela hegemonia na produção de atenção no campo da saúde mental.

Para tanto, utilizaremos a análise paradigmática desenvolvida por Costa-Rosa (2000; 2013), que delineia quatro parâmetros estruturais em busca de uma melhor elaboração teórica das lutas existentes nesse campo. Os parâmetros propostos são: a) a concepção do referente e dos meios de ação; b) as modalidades de relação intra e interinstitucionais; c) as modalidades de relação com o território e a população e sua recíproca; d) os efeitos produtivos em termos ético-políticos. Com base nisso, foram deduzidos dois paradigmas básicos em disputa em nosso momento histórico: o paradigma psiquiátrico hospitalocêntrico medicalizador (PPHM) e o paradigma psicossocial (PPS).

Por se tratar de uma elaboração conceitual que busca delimitar os traços fundamentais desses paradigmas, os seus parâmetros são apresentados em pares opostos muito bem delimitados. Essa abordagem revela sua pertinência ao permitir que, em meio à opacidade do cotidiano institucional, os atores implicados nesse campo possam estabelecer algumas coordenadas que os orientem em direção aos objetivos éticos almejados ela permite, portanto, aquilo a que chamamos de clareza paradigmática (COSTA-ROSA, 2013). Ela também se revela pertinente para nossos objetivos no presente trabalho na medida em que podemos nos apoiar em suas elaborações para definir com maior rigor as recentes mudanças na PNSM.

Temos então que o PPHM pode ser caracterizado por uma concepção que objetifica o sofrimento psíquico na forma de uma doença ou transtorno mental, e que utiliza meios de intervenção disciplinares, isto é, divididos em especialidades que pouco ou nada se relacionam entre si. Suas relações intra e interinstitucionais são marcadas pela verticalidade e concentração de poder nos estratos mais elevados de uma hierarquia, bem como por uma compartimentalização e consequente baixa articulação institucional, seja ela setorial ou intersetorial. As modalidades de relacionamento com a população e o território são marcadas pela dicotomia carência-suprimento (COSTA-ROSA, 2013) - seja este um suprimento moral ou medicamentoso - e pelo controle dos indivíduos desviantes; seus estabelecimentos são percebidos como espaços depositários e excludentes. Quanto ao efeito esperado em termos éticos, temos a produção de adaptação social e de subjetividade serializada, aquela que "individualiza o desejo" e "se presta a todo tipo de manipulação pelos equipamentos capitalísticos" (GUATTARI; ROLNIK, 1986, p. 233).

Em contraposição, o PPS se caracteriza pela consideração princeps do sujeito do sofrimento psíquico - evitando a sua objetificação em categorias de doença ou transtorno mental -, e por meios transdisciplinares de intercessão. As relações intrainstitucionais são horizontalizadas, estabelecendo a dissipação do poder por todos os níveis da instituição, sobretudo na direção do controle social exercido pela população; ao passo 


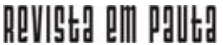

\} RETROCESSOS NA POLÍTICA NACIONAL - PASSARINHO, J. G. N. \}

DOI: $10.12957 /$ REP.2022.63451

que as relações interinstitucionais apresentam alto nível de articulação intra e intersetorial. Quanto às modalidades de relacionamento com a população e o território e sua recíproca, temos a valorização das potencialidades territoriais, em que se propõem relações de produção subjetiva e de (inter)locução - diálogo entre trabalhadores e sujeitos do sofrimento e fala protagonista destes últimos -, em espaços reconhecidos como lócus de escuta e atenção. O efeito esperado em termos éticos é a produção de subjetividade singularizada, assim chamada por "partir do sujeito como agente produtivo por excelência" (COSTA-ROSA, 2013, p. 68). Subjetividade homóloga à implicação ativa dos sujeitos nas contradições socioculturais que Ihes atravessam e a novas formas de sociabilidade em relação ao sofrimento psíquico.

\section{Tabela 1}

\begin{tabular}{|c|c|c|}
\hline & $\begin{array}{c}\text { paradigma psiquiátrico } \\
\text { hospitalocêntrico Medicalizador }\end{array}$ & paradigma psicossocial \\
\hline $\begin{array}{l}\text { Parâmetro 1: } \\
\text { concepção do referente } \\
\text { e dos meios de ação }\end{array}$ & $\begin{array}{l}\text { Transtorno ou doença mental como } \\
\text { objeto e meios disciplinares de } \\
\text { intervençāo. }\end{array}$ & $\begin{array}{l}\text { Consideraçào do sujeito do sofrimento } \\
\text { psiquico em sua complexidade, e meios } \\
\text { de intercessão em perspectiva } \\
\text { transdisciplinar. }\end{array}$ \\
\hline $\begin{array}{l}\text { Parâmetro 2: modos de } \\
\text { relação intra e } \\
\text { interinstitucionais }\end{array}$ & $\begin{array}{l}\text { Relaçôes intrainstitucionais } \\
\text { hierarquizadas em sentido verticalizado } \\
\text { (concentração do poder) e } \\
\text { interinstitucionais fragmentárias (baixo } \\
\text { nivel de articulaçào). }\end{array}$ & $\begin{array}{l}\text { Relaçōes intrainstitucionais } \\
\text { horizontalizadas (dispersào do poder) e } \\
\text { interinstitucionais consistentes (alto nivel } \\
\text { de articulaçào). }\end{array}$ \\
\hline $\begin{array}{l}\text { Parâmetro 3: modos de } \\
\text { relação com a } \\
\text { população e o território } \\
\text { e a recíproca }\end{array}$ & $\begin{array}{l}\text { Relaçóes de carência-suprimento e de } \\
\text { controle, em espaços vistos como lócus } \\
\text { depositário e excludente. }\end{array}$ & $\begin{array}{l}\text { Relaçóes de (inter)locuçào e produção } \\
\text { subjetiva, em espaços vistos como locus } \\
\text { de escuta, diálogo e atenção. }\end{array}$ \\
\hline $\begin{array}{l}\text { Parâmetro 4: efeitos } \\
\text { produtivos em termos } \\
\text { ético-políticos }\end{array}$ & $\begin{array}{l}\text { Produçào de subjetividade serializada e } \\
\text { adaptação social. }\end{array}$ & $\begin{array}{l}\text { Produçào de subjelividade singularizada } \\
\text { e transformação social. }\end{array}$ \\
\hline
\end{tabular}

\section{Por que falar em retrocesso?}

A partir da distinção paradigmática feita acima, pretendemos fazer algumas considerações sobre as mudanças recentes na política nacional de saúde mental (PNSM). A respeito da inclusão de estabelecimentos como as comunidades terapêuticas e os hospitais psiquiátricos na Rede de Atenção Psicossocial (Raps), podemos afirmar imediatamente que se trata de uma contradição em termos. A Raps foi instituída com o objetivo de funcionar de forma substitutiva à rede hospitalar que a precedeu, tendo entre os seus princípios a territorialidade e a reinserção social de indivíduos egressos de períodos prolongados de internação (BRASIL, 2011). Ora, como será 


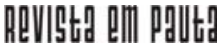

\} RETROCESSOS NA POLÍTICA NACIONAL - PASSARINHO, J. G. N. \}

DOI: $10.12957 /$ REP.2022.63451

possível efetivar essas diretrizes quando a própria Raps passa a incluir estabelecimentos que funcionam retirando os indivíduos de seu convívio social e, consequentemente, de seus vínculos com o território?

Neste ponto, podemos fazer referência mais direta aos parâmetros 1 e 3 da análise paradigmática: os dois estabelecimentos abordados funcionam como lócus de isolamento social (COSTA-ROSA, 2013; RAMÔA; TEIXEIRA; BELMONTE, 2019). Suas ofertas de atenção operam por meio da objetificação do sujeito, seja pela via da redução de sua existência à definição restrita de um diagnóstico psiquiátrico, pelo controle exaustivo do cotidiano dos internos, ou pela oferta de um suprimento moral ou medicamentoso (COSTA-ROSA, 2013). Desse modo, temos a concepção de um objeto de intervenção e a prescrição de meios disciplinares de intervenção, em estabelecimentos que buscam limitar ou até mesmo sustar o convívio social territorializado dos sujeitos.

Quanto ao Caps-AD IV, é possível fazer considerações semelhantes. A concepção de território apresentada nos documentos parece diferir consideravelmente daquela consagrada no campo da atenção psicossocial (LIMA; YASUI, 2014) - isso se dá na medida em que considera apenas sua dimensão estritamente geográfica. A noção de territorialidade em saúde, ao contrário, pressupõe um conjunto de relações sociais e a dinâmica de transformação que elas impõem ao espaço físico, bem como a utilização de suas potencialidades para o planejamento e execução de ações de atenção. Nesse sentido, é preciso considerar que mudar apenas o lócus da prática não é suficiente para alterar sua lógica de funcionamento e seus efeitos; ou seja, um serviço baseado em uma delimitação territorial puramente administrativa pode servir para a adaptação e o controle tanto quanto um estabelecimento manicomial (LIMA; YASUI, 2014).

Ao determinar a localização nas "cenas de uso" e o enfoque na "urgência e emergência" (BRASIL, 2017b), o documento parece indicar que considera esses espaços apenas como locais de risco e as ações a serem ali realizadas como essencialmente remediadoras. A disposição para a internação, indicada pelo número elevado de leitos permitidos, aponta para a lógica curativa, distante da prevenção e promoção. Ao invés da articulação com o território, o que se vê é a mitigação inerte dos efeitos mais danosos do uso pre-judicial de álcool e outras drogas. Assim, esse serviço surge como espaço de contenção de crises e remediação passiva - ao invés da redução ativa - de danos. Considerando o parâmetro 3, devemos situar essa modalidade de relacionamento com o território muito mais próxima do PPHM do que do PPS.

Ainda que isso não esteja dito de forma explícita nos documentos analisados, alguns autores defendem que as características do Caps-AD IV podem Ihe conferir a vocação para práticas de internações compulsórias e tendencialmente prolongadas, ou para funcionar como estabelecimento intermediário entre as cenas de uso e os hospitais psiquiátricos e comunidades terapêuticas (ONOCKO-CAMPOS, 2019; CRUZ; GON- 


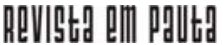

\} RETROCESSOS NA POLITICA NACIONAL - PASSARINHO, J. G. N. \}

DOI: $10.12957 /$ REP.2022.63451

CALVES; DELGADO, 2020). Também é questionada a possibilidade de se trabalhar com base no vínculo terapêutico e na territorialidade quando a capacidade máxima é de 30 leitos de enfermaria e sua localização é sempre nas cenas de uso - "como se estas pessoas não fossem mais nada na vida além de usuários de drogas" (CRUZ; GONCALVES; DELGADO, 2020, p. 7). Reduzir o sujeito à sua condição de adicto não é mais do que outra forma de objetificação, conduzindo-nos mais uma vez ao primeiro parâmetro da análise paradigmática.

A respeito da eletroconvulsoterapia, ela se situa entre os meios de intervenção típicos do PPHM, não apenas por ser uma técnica restrita da psiquiatria, mas sobretudo por tomar o sofrimento psíquico como disfunção neuroquímica, alheia, portanto, às suas determinações socioculturais e subjetivas (SILVA; CALDAS, 2008). Seguindo os critérios da análise paradigmática, essa também é uma forma de objetificação do sujeito, não por postular uma causalidade especificamente biológica do sofrimento psíquico - que não deixa de ser considerada pelo paradigma psicossocial -, mas na exata medida em que fica restrita apenas a essa instância de determinação. Isso porque, dessa maneira, perde-se de vista a perspectiva do protagonismo dos sujeitos do sofrimento que, no que concerne ao PPS, é absolutamente fundamental para a produção de repostas aos impasses que os acometem.

O histórico de uso dessa tecnologia em estabelecimentos manicomiais também é um fator que precisa ser considerado. Sabe-se que a ECT foi amplamente utilizada para a contenção de pacientes considerados "agressivos", ou seja, como instrumento de repressão e castigo. Visava-se, nesses casos, a um efeito de adaptação e docilização, em congruência com a ética típica do PPHM, descrita no parâmetro 4. Mesmo que se argumente que existem diversos estabelecimentos que atualmente utilizam a ECT de forma dita adequada, isto é, segundo protocolos reconhecidos de indicação e segurança, não se pode desconsiderar o risco da reincidência de práticas punitivas ou de efeitos iatrogênicos.

Além disso, ainda hoje existe uma inegável controvérsia sobre a eficácia, eficiência e segurança dessa forma de intervenção. Alguns estudos defendem o seu uso em casos graves de depressão não responsivos aos psicofármacos e em alguns quadros psicóticos, baseando-se principalmente em revisões de estudos realizados a partir dos anos 1980 (PERIZZOLO et al., 2003; MOSER; LOBATO; ABREU, 2005; ANTUNES et al., 2009). Contudo, outros trabalhos questionam tais indicações, argumentando que boa parte do conhecimento produzido sobre o tema nas últimas décadas padece de vieses e conflitos de interesse (OLIVEIRA, 2019), ou que o desenho epistemológico, a concepção do objetivo terapêutico e os fundamentos éticos desses estudos divergem radicalmente daqueles postulados pela RPb (SILVA; CALDAS, 2008).

Diferentes artigos de revisão sistemática corroboram com a acusação de enviesamento e apontam para a inconclusividade acerca da eficácia 


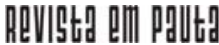

\} RETROCESSOS NA POLÍTICA NACIONAL - PASSARINHO, J. G. N. \}

DOI: $10.12957 /$ REP.2022.63451

e segurança do tratamento (STEK et al., 2003; THARYAN; ADAMS, 2005; SINCLAIR et al., 2019). Alguns destacam o desconhecimento do seu mecanismo de ação e a possível gravidade de seus efeitos colaterais, especialmente dos distúrbios de memória, muitas vezes subestimados por seus defensores (SILVA; CALDAS, 2008; OLIVEIRA, 2019). Outros falam da escassez de produções sobre seu uso no contexto brasileiro (MACHADO et al., 2018). Portanto, está claro que estamos diante de uma discussão no mínimo polêmica e certamente inconclusa sobre a validade da ECT, algo muito distante da afirmação feita na Nota Técnica n 11/2019, que fala em "robustas evidências científicas" para incentivar o seu uso e financiamento com recursos públicos (BRASIL, 2019, p. 6).

\section{Conclusão}

Buscamos situar um conjunto de alterações recentes na política nacional de saúde mental na perspectiva de uma análise teórico-conceitual da luta por hegemonia paradigmática no campo da saúde mental e suas instituições, que em nosso momento histórico se dá entre o paradigma psiquiátrico hospitalocêntrico medicalizador e o paradigma psicossocial. Para justificar o emprego de termos como "retrocessos" e "contrarreforma", destacamos os critérios éticos e políticos que contrapõem as novas propostas em relação aos postulados do paradigma pertinente à atenção psicossocial, levando a discussão sobre o tema para além das questões estritamente técnicas, que não deixam de conservar sua importância como um dos diversos aspectos do problema estudado.

Certamente não queremos desconsiderar a dimensão técnico-assistencial envolvida no debate. Ao insistirmos na importância de se enfatizar também as implicações éticas e políticas e na necessidade ainda premente de transformação das formas de sociabilidade como horizonte maior da atenção psicossocial, não perdemos de vista o objetivo terapêutico. A denúncia ao enclausuramento e à objetificação dos sujeitos busca evitar os conhecidos efeitos iatrogênicos do modelo manicomial. Ao mesmo tempo, na medida em que se reconhece e garante o estatuto de protagonista dos sujeitos na produção de respostas ao seu próprio sofrimento, tendo os trabaIhadores como intercessores necessários, espera-se um ganho de eficiência em favor da saúde no processo de saúde-adoecimento pela via da atenção.

Conforme buscamos demonstrar, o conteúdo dos documentos analisados converge em grande medida com o modelo que vigorava antes da experiência da reforma psiquiátrica brasileira e de seus desdobramentos - e isso independe do fato de ele agora se apresentar com novos argumentos e tecnologias, posto que isso não alterou em nada os seus antigos pressupostos e traços fundamentais. Nesse sentido, consideramos importante aprofundar o debate sobre a política nacional de saúde mental como forma de 


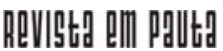

\} RETROCESSOS NA POLÍTICA NACIONAL - PASSARINHO, J. G. N. \}

DOI: $10.12957 /$ REP.2022.63451

reorganizar um discurso crítico em nosso campo, tão necessário frente ao cenário de retrocesso que se apresenta diante de nós. 


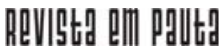

\} RETROCESSOS NA POLÍTICA NACIONAL - PASSARINHO, J. G. N. \}

DOI: $10.12957 /$ REP.2022.63451

\section{Referências}

AMARANTE, P. O homem e a serpente: outras histórias para a loucura e a psiquiatria. Rio de Janeiro: Fundação Oswaldo Cruz, 1996.

AMARANTE, P. (Org.). Loucos pela vida: a trajetória da reforma psiquiátrica no Brasil. Rio de Janeiro: Editora Fiocruz, 2000.

ANTUNES, P. B. et al. Eletroconvulsoterapia na depressão maior: aspectos atuais. Rev. Bras. Psiquiatr., São Paulo, v. 31, supl. 1, maio 2009.

BASAGLIA, F. A instituição negada: relato de um hospital psiquiátrico. Rio de Janeiro: Graal, 2001.

BRASIL. Ministério da Saúde. Portaria n. 3.088, de 23 de dezembro de 2011. Institui a Rede de Atenção Psicossocial para pessoas com sofrimento ou transtorno mental e com necessidades decorrentes do uso de crack, álcool e outras drogas, no âmbito do Sistema Único de Saúde (SUS). Diário Oficial, Brasília, 2011.

BRASIL. Ministério da Saúde. Secretaria de Atenção à Saúde. Portaria n. 1.482 , de 25 de outubro de 2016. Inclui na tabela de tipos de estabelecimentos de saúde do cadastro nacional de estabelecimentos de saúde: CNES o tipo 83: polo de prevenção de doenças e agravos de promoção da saúde. Diário Oficial, Brasília, 2016.

BRASIL. Ministério da Saúde. Comissão Intergestores Tripartite. Resolução n. 32, de 14 de dezembro de 2017. Diário Oficial, Brasília, 2017 a.

BRASIL. Ministério da Saúde. Portaria n. 3.588, de 21 de dezembro de 2017. Altera as portarias de consolidação no 3 e no 6 , de 28 de setembro de 2017, para dispor sobre a Rede de Atenção Psicossocial, e dá outras providências. Diário Oficial, Brasília, 2017b.

BRASIL. Secretaria de Atenção à Saúde. Portaria n. 544, de 7 de maio de 2018. Define diretrizes para o cadastro do novo porte de Centro de Atenção Psicossocial de Álcool e Outras Drogas do Tipo IV (Caps-AD IV) Cadastro Nacional de Estabelecimentos de Saúde (CNES) e dá outras providências. Diário Oficial, Brasília, 2018.

BRASIL. Ministério da Saúde. Nota Técnica n. 11/2019: esclarecimentos sobre as mudanças na política nacional de saúde mental e nas Diretrizes da Política Nacional sobre Drogas. Brasília, 2019.

COSTA-ROSA, A. O modo psicossocial: um paradigma das práticas substitutivas ao modo asilar. In: AMARANTE, P. (Org.). Ensaios: subjetividade, saúde mental, sociedade. Rio de Janeiro: Fiocruz, 2000. 


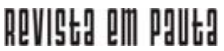

\} RETROCESSOS NA POLÍTICA NACIONAL - PASSARINHO, J. G. N. \}

DOI: $10.12957 /$ REP.2022.63451

COSTA-ROSA, A. Atenção psicossocial além da reforma psiquiátrica: contribuição a uma clínica crítica dos processos de subjetivação na saúde coletiva. São Paulo: Unesp, 2013.

CRUZ, N. F. O.; GONCALVES, R. W.; DELGADO, P. G. G. Retrocesso da reforma psiquiátrica: o desmonte da política nacional de saúde mental brasileira de 2016 a 2019. Trab. educ. saúde, Rio de Janeiro, v. 18, n. 3, 2020.

DEVERA, D.; COSTA-ROSA, A. Marcos históricos da reforma psiquiátrica brasileira: Transformações na legislação, na ideologia e na práxis. Revista de Psicologia da Unesp, Assis, v. 6, n. 1, jan./dez. 2007.

GUATTARI, F.; ROLNIK, S. Micropolítica: cartografias do desejo. Petrópolis: Vozes, 1986.

LIMA, E. M. F. A.; YASUI, S. Territórios e sentidos: espaço, cultura, subjetividade e cuidado na atenção psicossocial. Saúde Debate, Rio de Janeiro, v. 38, n. 102, jul./set. 2014.

MACHADO, F. B. et al. Eletroconvulsoterapia: implicações éticas e legais. Rev. Cient. Sena Aires, Goiânia, v. 7, n. 3, out./dez. 2018.

MINISTÉRIO DA SAÚDE. Nota: saúde mental. 8 dez. 2020. Disponível em: https://aps.saude.gov.br/noticia/10539. Acesso em: 10 out. 2021.

MONDONI, D.; COSTA-ROSA, A. Reforma psiquiátrica e transição paradigmática no interior do estado de São Paulo. Psicologia: teoria e pesquisa, Brasília, v. 26, n. 1, jan./mar. 2010.

MORAES FILHO, I. M. et al. Retrocesso nas políticas nacionais de saúde mental e de álcool e outras drogas no brasil a partir da nota técnica n. 11/ 2019. Revisa, Valparaíso, v. 8, n. 2, 2019.

MOSER, C. M.; LOBATO, M. I.; ABREU, P. B. Evidências da eficácia da eletroconvulsoterapia na prática psiquiátrica. Rev. Psiquiatr, Porto Alegre, v. 27, n. 3, dez. 2005.

NUNES, M. O. et al. Reforma e contrarreforma psiquiátrica: análise de uma crise sociopolítica e sanitária a nível nacional e regional. Ciênc. saúde coletiva, Rio de Janeiro, v. 24, n. 12, dez. 2019.

OLIVEIRA, W. F. Eletroconvulsoterapia (ECT)/eletrochoque: a produção de evidências sobre uso, eficácia e eficiência. Cad. Bras. Sau. Ment., Florianópolis, v. 11, n. 28, 2019.

ONOCKO-CAMPOS, R. T. Saúde mental no Brasil: avanços, retrocessos e desafios. Cadernos de Saúde Pública, Rio de Janeiro, v. 35, n. 11, out. 2019.

PASSARINHO, J. G. N. O DSM como ideologia: uma crítica do Manual Diagnóstico na perspectiva da luta paradigmática em saúde mental. Disser- 
tação (Mestrado em Psicologia) - Faculdade de Ciências e Letras, Universidade Estadual Paulista "Júlio de Mesquita Filho", Assis, 2020.

PASSOS, R. Luta antimanicomial no cenário contemporâneo: desafios atuais frente a reação conservadora. Socied. em deb., Pelotas, v. 23, n. 2, jul./ dez. 2017.

PERIZZOLO, J. et al. Aspectos da prática da eletroconvulsoterapia: uma revisão sistemática. Rev. psiquiatr., Rio Grande do Sul, v. 25, n. 2, maio/ ago. 2003.

RAMÔA, M.; TEIXEIRA, M. B.; BELMONTE, P. As comunidades terapêuticas no cenário das políticas públicas: o retorno das práticas institucionalizantes. Platô: Drogas e política, São Paulo, v. 3, n. 3, jul. 2019.

SILVA, M. L. B.; CALDAS, M. T. Revisitando a técnica da eletroconvulsoterapia no contexto da reforma psiquiátrica brasileira. Psic. Cien. Prof., v. 28, n. 2, 2008.

SILVA, T. A. et al. (Re)visitando a reforma psiquiátrica brasileira: perspectivas num cenário de retrocessos. Av. Enferm., Bogotá, v. 38, n. 3, jan. 2021.

SINCLAIR, D. J. M. et al. Electroconvulsive therapy for treatment resistant schizophrenia. Schizophrenia Bulletin, v. 45, n. 4, jul. 2019.

STEK, M. L. et al. Electroconvulsive therapy for the depressed elderly. Coch. Data. Syst. Rev., n. 2, 2003.

THARYAN, P.; ADAMS, C. E. Eletroconvulsive therapy for schizophrenia. Coch. Data. Syst. Rev., v. 18, n. 2, abr. 2005.

VASCONCELOS, E. M. Reforma psiquiátrica, tempos sombrios e resistência: diálogos com o marxismo e o Serviço Social. Campinas: Editora Papel Social, 2016.

YASUI, S. Rupturas e encontros: desafios da reforma psiquiátrica brasileira. Rio de Janeiro: Editora Fiocruz, 2010.

YASUI, S.; COSTA-ROSA, A. A Estratégia Atenção Psicossocial: desafio na prática dos novos dispositivos de Saúde Mental. Saúde em Debate, Rio de Janeiro, v. 32, n. 78-79-80, 2008.

DOI: $10.12957 /$ rep.2022.63451

Recebido em 24 de junho de 2021.

Aprovado para publicação em 06 de outubro de 2021.

A Revista Em Pauta: Teoria Social e Realidade Contemporânea está licenciada com uma Licença Creative Commons Atribuição 4.0 Internacional. 